\title{
Development and validation of a protocol for cell line identification by MALDI-TOF MS
}

\author{
Guido Vogel ${ }^{1 *}$, André Strauss ${ }^{1}$, Bernard Jenni ${ }^{1}$, Dominik Ziegler ${ }^{1}$, Eric Dumermuth², Sylvie Antz², \\ Claudia Bardouille $^{3}$, Beat Wipf ${ }^{3}$, Christian Miscenic ${ }^{3}$, Georg Schmid $^{3}$, Valentin Pflüger ${ }^{1}$ \\ From 22nd European Society for Animal Cell Technology (ESACT) Meeting on Cell Based Technologies \\ Vienna, Austria. 15-18 May 2011
}

\section{Summary}

Misidentification or cross-contamination of cell lines used in biotechnology or diagnostic settings are a challenge for laboratories and cell culture repositories. Masters et al. [1] among others reported the occurrence of large numbers of unrecognized and unreported misidentification or cross-contamination of cell lines. Current methods for the authentication of cell lines such as karyotyping, 2D-gel-electrophoresis, restriction fragment length polymorphism (RFLP) or short tandem repeats (STR) are expensive, labor intensive and not routinely applied. In the last decade MALDI-TOF MS became a powerful tool for the rapid and cost effective identification and taxonomic classification of microorganisms directly from whole cell extracts. We adapted this protein fingerprinting approach for a fast species identification of eukaryotic cell lines and established as well as validated a reference database.

In addition we demonstrate that this new approach has a potential for the rapid characterization of recombinant protein expression systems. Accurate protein expression and the determination of the molecular mass of the recombinant expressed proteins $(20-120 \mathrm{kDa})$ can directly be analyzed from stable transfected and virus infected cultures.

\section{Materials and methods}

$1 \mathrm{ml}$ of fresh culture was transferred into an Eppendorf tube and washed once with $1 \mathrm{x}$ PBS. The pellet was resuspended in $70 \% \mathrm{EtOH}$ for transport and storage at RT. $1 \mu \mathrm{l}$ of the cell pellet was transferred with a plastic loop to a new Eppendorf tube and mixed with $20 \mu \mathrm{l}$ formic acid (10\%). The suspension was mixed with $40 \mu \mathrm{l}$ of

\footnotetext{
* Correspondence: guido.vogel@mabritec.com

${ }^{1}$ Mabritec AG, 4125 Riehen, Switzerland

Full list of author information is available at the end of the article
}

saturated sinapinic acid matrix. $1 \mu \mathrm{l}$ of sample suspension was spotted on a steel target plate in duplicates. Spectra were acquired on Shimadzu Confidence MALDI-TOF MS in linear mode in a mass range from 2-50kDa. Peak lists were imported into SARAMIS software for Marker pattern definition and automated identification.

\section{Results}

In a first phase we analyzed 146 different eukaryotic cell lines derived from 11 different taxa (Figure 1), including common lines from culture collections as well as customer specific in-house lines. Marker patterns were established for these 11 taxa and validated in a blinded study with 9 mammalian and 48 insect cell lines. All 57 test samples were correctly identified on the species level. Even two intentionally mixed samples were assigned to the right species.

In a second phase we analyzed more than 178 mammalian and 240 insect cell lines for identity authentication from different customers in order to evaluate the usefulness of this service. Out of 418 samples analyzed, we revealed 6 samples with either wrong identities, strongly altered or unknown mass profiles (Table 1).

When necessary cell lines were also analyzed for their expression profile after infection or transfection with viral vectors. It was possible to determine precise masses of overexpressed proteins as compared to controlled samples. For these additional experiments, no further sample preparation was necessary.

\section{Conclusion}

We developed a fast, simple and accurate method with high throughput capacity for the authentication of cell 


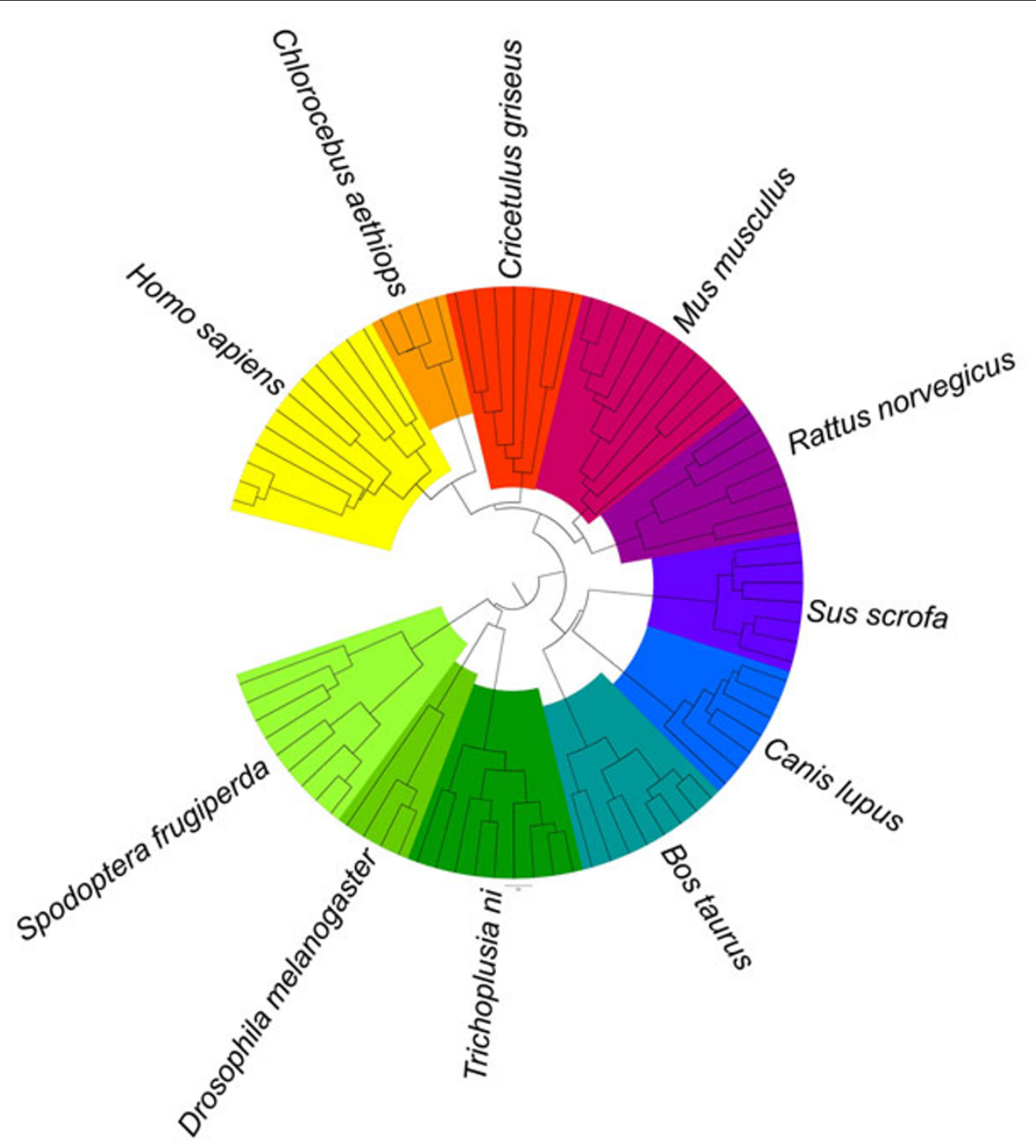

Figure 2:Cluster analysis of MALDI-TOF MS spectra from 92 different cell lines

Figure 1 Cluster analysis of MALDI-TOF MS spectra from 92 different cell lines

lines. Since the construction of customer specific mass profile libraries is straightforward, we propose this approach as an additional method for routine cell line authentication in biotechnology settings.

Further we demonstrated that MALDI-TOF MS is also a fast and simple tool for the characterization of eukaryotic protein expression systems, especially for the determination of a precise mass.

\section{Author details}

${ }^{1}$ Mabritec AG, 4125 Riehen, Switzerland. ${ }^{2}$ Novartis Pharma AG , 4056 Basel, Switzerland. ${ }^{3} \mathrm{~F}$. Hoffmann-La Roche AG, 4070 Basel, Switzerland.

Table 1 Example of problematic samples

\begin{tabular}{lll}
\hline sample name & expected species & MALDI-TOF MS results \\
\hline Sf9 & Spodoptera frugiperda & Trichoplusia ni \\
HepG2 & Homo sapiens & Mus musculus \\
SK-MEL-30 & Homo sapiens & Homo sapiens profile with strongly altered mass composition: contamination possible \\
CHO-K1 & Cricetulus griseus & unknown mass profile \\
J558L & Mus musculus & Mus musculus profile with strongly altered mass composition: contamination possible \\
WS1 & Homo sapiens & unknown mass profile \\
\hline
\end{tabular}


Published: 22 November 2011

\section{Reference}

1. Masters $J R$, et al: Short tandem repeat profiling provides an international reference standard for human cell lines. PNAS 2001, 98:8012-8017.

doi:10.1186/1753-6561-5-S8-P45

Cite this article as: Vogel et al:: Development and validation of a protocol for cell line identification by MALDI-TOF MS. BMC Proceedings 2011 5(Suppl 8):P45.

Submit your next manuscript to BioMed Central and take full advantage of:

- Convenient online submission

- Thorough peer review

- No space constraints or color figure charges

- Immediate publication on acceptance

- Inclusion in PubMed, CAS, Scopus and Google Scholar

- Research which is freely available for redistribution

Submit your manuscript at www.biomedcentral.com/submit
C Biomed Central 